\title{
Traumatic tympanic membrane perforations: characteristics and factors affecting outcome
}

\author{
Olusola A Sogebi, Emmanuel A Oyewole and Taofeeq O Mabifah
}

Ghana Med J 2018; 52(1): 34-40 DOI: http://dx.doi.org/10.4314/gmj.v52i1.7

Department of Ear Nose and Throat, Olabisi Onabanjo University Teaching Hospital, Sagamu, Nigeria

Corresponding author: Dr Olusola Ayodele Sogebi

e-mail: ayosogebi2000@yahoo.com

Conflict of interest: None declared

\begin{abstract}
SUMMARY
Objective: To characterize traumatic tympanic membrane perforation (TTMP) in terms of distribution, mechanisms, and outcome of treatment. To assess the factors influencing such outcome.

Study design: Prospective analytical study, assessing outcomes post-injuries.

Setting: Clinical department of a tertiary referral hospital.

Participants: Patients with TTMP based on history of trauma to the ear, and otoscopic examination confirming tympanic membrane (TM) perforation.

Intervention(s): Conservative, inactive treatment.

Main Outcome Measure(s): Distribution and healing of perforations

Results: There were 53 patients, Male: Female ratio $=1.5$ : 1 , age 8-71years (Mean $\pm \mathrm{SD}=33.8 \pm 12.9$ ). Median duration of injury before presentation was 3 days. 11 patients had both ears traumatized. $46.9 \%$ of perforations were in the antero-inferior part of the TM. Median size of perforations was 33.0\%; Patients main complaints were blockage of the ears/ hearing loss and tinnitus. Common causes of perforations were domestic assault (28.3\%), self-inflicted/ accidental injuries (20.8\%), and road traffic accidents (18.9\%). There was a significant difference in the mechanism/cause of injuries between the sexes $\left(\mathrm{X}^{2}=15.607, \mathrm{p}=0.005\right)$. Traumatic perforation was caused by penetrating injuries in 22 (34.4\%) ears. The outcome of TTMP was poor in $18.7 \%$. Big sized perforations $(t=2.630 ; p=0.011)$, penetrating injuries $\left(X^{2}=9.263 ; p=0.005\right)$, and postero-superior location $\left(X^{2}=6.326 ; p=0.009\right)$ had negative impacts on the healing. Conclusions: TTMP was common in young adult males, caused often by assaults, presented with ear hearing loss and tinnitus, perforations were located in antero-inferior part of TM and most healed well. Factors associated with poor healing were postero-superior location, large size and penetrating injuries to the TM.
\end{abstract}

Funding: Not indicated

Keywords: trauma; perforation; tympanic membrane; healing; outcome

\section{INTRODUCTION}

Trauma remains a regular occurrence relating to activities and lifestyle of humans and it can affect any part of the body. The ear is located within the cranio-facial skeleton which is exposed to environmental trauma that can occur as blunt injuries like contusion, concussion, decompression, and penetrating injuries as fractures. ${ }^{1} \mathrm{Ma}-$ jor injuries affecting the ears can lead to disturbances in hearing and difficulties in maintenance of balance especially when the inner ear is affected.,3 More of ear trauma however affect either the bony skeleton or soft tissue structures within the external and middle ear. Ear injuries may lead to lacerations in the external ear, and disruption of the ossicular chain in the middle ear cavity.
The tympanic membrane (TM) is a delicate translucent fibrous membrane which separates the external from the middle ear, and it produces a rupture, tear or perforation when traumatized. The TM injury can predispose to middle ear infection which has grave consequences including facial nerve paralysis, formation of cholesteatoma, perilymph fistula, intracranial infections and may require ear and intracranial exploration. ${ }^{4}$ Significant morbidity or mortality can occur when traumatic ear injuries are associated with damage to contiguous facial structures and the brain. Effective management is expedient while prevention and reduction of complications must be given utmost attention to achieve a good outcome. 


\section{Original Article}

The outcome may also be related to the cause, mechanism, treatment and complications associated with the injuries.

Simple traumatic tympanic membrane perforation (TTMP) remains the most common type of trauma - induced otologic dysfunction. ${ }^{5}$ Treatment of TTMP range from inactive watchful waiting, active intervention to surgical intervention. ${ }^{6}$ Otolaryngologists have however been advised to be reluctant in offering surgical intervention in cases of TTMP without significant symptoms as most patients will heal spontaneously within two months. ${ }^{7}$ Active interventions include topical application of substances like epidermal growth factor, enoxaparin, and ascorbic acid ${ }^{\text {to }}$ stimulate epithelization for quick closure or to prevent formation of sclerotic plaques in the perforated membrane. ${ }^{8,9,10}$

Surgical intervention are indicated in cases of complications like perilymph fistula, facial paralysis, severe vertigo, or profound sensorineural hearing loss. Such diagnosis should be made early and treatment offered promptly. ${ }^{7}$ Surgical treatment included exploration and tympanoplasties, closure of the perforation with stents in the form of simple patches, ${ }^{11}$ or as patches laden with substances in the form of silk fibroin membranes, ${ }^{12}$ or steri-strips patching. ${ }^{13}$ These technical surgeries require high expertise and necessary equipment which may not be readily available in the low socio-economic countries. In such less ideal situations, it will be necessary to characterize traumatic tympanic membrane (TM) perforation if optimal treatment is desirable. Our hospital is a relatively high volume trauma center and cases of injuries to the ears involving the tympanic membranes are readily seen. Characterizing such lesion will provide an impetus for better management of affected patients.

This study aims to characterize the TTMP in terms of distribution, mechanisms or causes of injuries and outcome of intervention. It also assesses factors that can influence the outcome of the TM perforation. This should assist in proper management and hopefully enhance good outcome.

\section{METHODS}

This is a prospective analytical study of patients that were seen between January 2012 and June 2016, at the Ear, Nose and Throat (ENT) department of a University Teaching Hospital in Nigeria. Consecutive patients were seen in the ENT Clinic and the Accident and Emergency unit of the hospital. Patients were diagnosed to have TTMP based on history of trauma to the ear, and otoscopic examination confirming tear or perforation of the $\mathrm{TM}$ in the patients.
All consenting patients that met the above criteria were included in the study. However, patients that had previous external or middle ear disease, unconscious patients, multiply-injured patients that were referred to other centers, those in whom the TM could not be assessed for any reason and those who did not complete minimum followup visit of six weeks post-injury were excluded. Ethics approval for the study was obtained from the Health Research Ethics Committee (HREC) of the hospital.

Information obtained from the patients were socio-demographic and clinical parameters; the main cause of injury, the mechanism (differentiated as non-penetrating or penetrating injury to the TM) the affected ear(s), duration of injury before index presentation, previous interventions, and treatment employed. The outcome of the injury as regards healing of the perforation were also assessed at minimum of six weeks post-injury. It was the same surgeon who assessed and documented the extent of the injury initially that made the final assessments in terms of outcome.

Outcome of injury in terms of healing assessment at minimum of six weeks post injury were assessed in terms of closure of the TM perforation and complications like infection, formation of permanent perforation, or polypoidal growth. Outcome was thus classified as Good in complete or partial closure of perforation without complications and Poor in non-closure of perforation, or development of complications.

The information obtained was entered into a spread sheet and presented as descriptive and analytic statistics as tabular and graphical data. The categorical variables were presented as proportions and continuous variables were described as means or medians as applicable. Analytic statistics was assessed for discrete variables with chi square test, and for continuous variables with independent sample t-test. The level of statistical significance was taken as $\mathrm{p}<0.05$. The analyses were done using the SPSS version 20.0 (Chicago, Il, USA).

\section{RESULTS}

There were 98 patients with TTMP constituting $47.8 \%$ of the total number of 205 patients with various forms of ear trauma seen in the study period. Among the 98 patients, 53 had sufficient clinical data for inclusion in the study. There were 32 males and 21 females with Male : Female ratio of 1.5:1 The ages of the patients ranged between 8 and 71 years, the age group 21-30 years had the highest frequency (total of $35.8 \%$ ) among both males (34.4\%) and females $(38.1 \%)$. 
Duration of injury before presentation ranged between few hours and 23 days (median duration was 3 days). There was almost equal affectation of each ear although 11 patients had both ears (total 64 ears) traumatized. Almost half $(46.9 \%)$ of the perforations were located in the antero-inferior part of the TM. The estimated sizes of the perforations varied from 10.0-75.0 \% but median was $33.0 \%$, which was used to categorize such into either small or big-sized perforation. The main complaints of the patients were blockage of the ears/ hearing loss and tinnitus.

Table 1 depicts the demographic and clinical distribution of the patients whilst Figure 1 is the graphical representation of the frequency of occurrence of traumatic TM perforation in relation to age group and sex of the patients.

Table 1 Socio-demographic characteristics of the 53 patients

\begin{tabular}{|c|c|c|}
\hline Parameter & Number (n) & Percentage (\%) \\
\hline Age range (years) & $\begin{array}{l}8-71 \\
\text { Mean } \quad \pm \mathrm{SD}=\quad 33.8 \\
\pm 12.9\end{array}$ & \\
\hline Sex: Male & 32 & 60.4 \\
\hline Female & 21 & 39.6 \\
\hline $\begin{array}{l}\text { Range of duration of } \\
\text { symptoms (days) }\end{array}$ & $\begin{array}{l}0-23 \\
\text { Median }=3.0\end{array}$ & \\
\hline Side of ear affected: Right & 20 & 37.7 \\
\hline Left & 22 & 41.5 \\
\hline Bilateral & 11 & 20.8 \\
\hline \multicolumn{3}{|c|}{ Site of tympanic membrane perforation (64 ears) } \\
\hline Anterior & 30 & 46.9 \\
\hline Posterior & 18 & 28.1 \\
\hline Undefined & 16 & 25.0 \\
\hline $\begin{array}{l}\text { Range of size of perfora- } \\
\text { tion }\end{array}$ & $\begin{array}{l}10.0-75.0 \\
\text { Median }=33.0\end{array}$ & \\
\hline \multicolumn{3}{|c|}{ Major complaints of patients } \\
\hline Ear blockage/hearing loss & 34 & 64.2 \\
\hline Tinnitus & 27 & 50.9 \\
\hline Otalgia & 22 & 41.5 \\
\hline Otorrhoea & 8 & 15.1 \\
\hline$\underline{\text { Vertigo }}$ & $\underline{3}$ & 5.7 \\
\hline
\end{tabular}

Overall, the common causes of the perforations were domestic assault in 15 patients (28.3\%), self-inflicted/ accidental injuries in $11(20.8 \%)$ patients, and road traffic accidents in 10(18.9\%) patients. The mechanisms and types of the injuries in the TM perforations were charted according to sex in Table 2 .

Whereas self-inflicted and road traffic accident-related injuries were prominent causes among the males, domestic assault and self-inflicted injuries were the prominent causes among the females.
There was a significant difference in the mechanism/cause of injuries between the sexes (Chi square $=15.607, p=0.005$ ). Traumatic perforation was caused by penetrating injuries in $22(34.4 \%)$ ears. The outcome in terms of healing of the traumatic TM perforation after minimum of six weeks of the injury was adjudged to be good in $52(81.3 \%)$ ears comprising $35(54.7 \%)$ with complete healing and $17(26.7 \%)$ with partial healing without complication, while it was poor in $12(18.7 \%)$ ears.

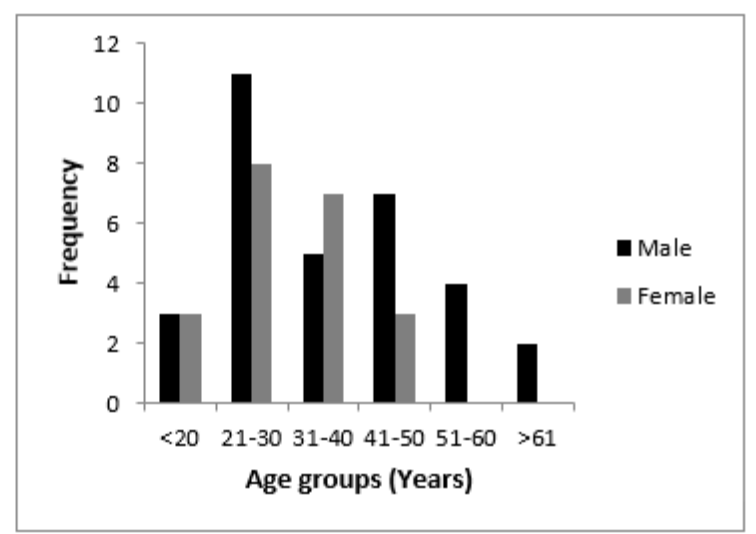

Figure 1 Frequency of TTMP in different age groups and sex

Table 2 Mechanisms and types of traumatic perforations according to sex

\begin{tabular}{llll}
\hline Mechanism of injury & \multicolumn{1}{c}{$\begin{array}{c}\text { Male } \\
\mathbf{n}=\mathbf{3 2}(\mathbf{\%})\end{array}$} & $\begin{array}{c}\text { Female } \\
\mathbf{n = 2 1 ( \% )}\end{array}$ \\
\hline Self-inflicted & $7(21.9)$ & $4(19.0)$ & \\
Road traffic accidents & $8(25.0)$ & $2(9.5)$ & \\
Domestic assault & $4(12.5)$ & $11(52.4)$ & \\
Community fracas/assault & $4(12.5)$ & $0(0.0)$ & \\
Armed robbery & $1(3.1)$ & $2(9.5)$ & \\
Security personnel assault & $5(15.6)$ & $0(0.0)$ & $\mathrm{X}^{2}=15.607$ \\
Others & $3(9.4)$ & $2(9.5)$ & $\mathrm{p}=0.005$ \\
Type of injury & & & \\
Non-penetrating & $17(53.1)$ & $14(66.7)$ & $\mathrm{X}^{2}=1.776$ \\
Penetrating & $15(46.9)$ & $7(33.3)$ & $\mathrm{p}=0.253$ \\
\hline
\end{tabular}

The clinical parameters that could be associated with the outcome of the perforation were explored in Table 3. It revealed that big size of perforation $>33 \%$ of the circumference of the TM $(t=2.630 ; p=0.011)$, penetrating injuries $\left(\mathrm{X}^{2}=9.263 ; \mathrm{p}=0.005\right)$, and postero-superiorly located perforations $\left(X^{2}=6.326 ; p=0.009\right)$ had negative impacts on the healing of the perforations. 


\section{Original Article}

Table 3 Factors associated with outcome of traumatic perforations

\begin{tabular}{|c|c|c|c|}
\hline \multirow[t]{2}{*}{ Factor } & \multicolumn{3}{|c|}{ Outcome } \\
\hline & Good & Poor & p-value \\
\hline Age in years (Mean) & 32.4 & 40.9 & 0.072 \\
\hline Sex (Male) & $56.8 \%$ & $77.8 \%$ & 0.291 \\
\hline $\begin{array}{l}\text { Affected ear (Bilat- } \\
\text { eral) }\end{array}$ & $20.5 \%$ & $22.2 \%$ & 0.905 \\
\hline $\begin{array}{l}\text { Duration of symp- } \\
\text { toms (Mean) }\end{array}$ & 5.9 & 6.1 & 0.961 \\
\hline $\begin{array}{l}\text { Size of perforation } \\
\text { (Mean) }\end{array}$ & 32.7 & 45.7 & 0.011 \\
\hline Previous intervention & $61.4 \%$ & $55.6 \%$ & 0.151 \\
\hline $\begin{array}{l}\text { Type of injury (Pene- } \\
\text { trating) }\end{array}$ & $25.0 \%$ & $75.0 \%$ & 0.005 \\
\hline $\begin{array}{l}\text { Location of perfora- } \\
\text { tion (Posterior) }\end{array}$ & $23.1 \%$ & $50.0 \%$ & 0.009 \\
\hline
\end{tabular}

\section{DISCUSSION}

The tympanic membrane is a delicate membrano-fibrous structure that is often violated in physical injuries to the ear. The affectation of TM in $47.8 \%$ of cases of ear trauma found in this study was marginally higher than the frequency of $44.0 \%$ reported over a decade ago in our center. ${ }^{14}$ While these values are close and there may not be a significant difference, it may suggest that physical injuries to the ear is not on a downward trend in our environment. TTMP perforation was more common in the active young age groups, as reflected in the mean age of 33.8 years found in this study. Other reports had age ranges of 29.2 to 33.6 years. ${ }^{15,16,17}$ The male preponderance found in our study resonates with that reported in a study in Ilorin, North-central Nigeria. ${ }^{15}$ This may be due to more outdoor activities in males than the females.

Traumatic injuries are often sporadic in occurrence and are mostly unplanned events thus patients who sustain such injuries consult the nearest available doctor for initial evaluation. About three quarter $(73.6 \%)$ of the patients in this study had been evaluated initially by nonspecialist Otolaryngologist. This may also connote scarcity of needed specialists in our locality. Nevertheless, most patients still presented and were reviewed by Otolaryngologists within 72 hours of the injuries. These relatively-early presentation might not be unconnected with the disturbing symptoms which evoked some anxiety in the patients. The common presenting symptoms of our patients were hearing loss $(64.2 \%)$, tinnitus $(50.9 \%)$ and ear ache $(41.5 \%)$ similar to previous reports in other studies. ${ }^{18,19}$ The presenting symptoms may be related to the severity and extent of the injuries as $20.8 \%$ of our patients had both TMs affected.
The reason for the slight preponderance of the left compared to the right ear found in this study is not clear. Sarojamma et al, ${ }^{17}$ however opined that it may be due to the fact that slap was a major etiological factor and a righthanded person tends to slap the victim over the left ear.

Exploration of the causes and mechanisms of TTMP revealed a trend similar to those reported from other studies. ${ }^{15,18}$ Assault (altogether 50.9\%) was a common and prominent cause of TTMP in this study like in other previous reports (37.4-86.4\%). ${ }^{16,19,20}$ Assaults ranged from domestic attacks like slaps from spouse and armed bandits, to injuries inflicted by state security personnel. In Germany, slaps with the open hand was the most common cause of TTMP. ${ }^{20}$ There was a significant difference in the mechanisms of injuries in the sexes of the patients. While RTA and assault by security personnel were common among the male patients, domestic assaults was prominent among the females. Lou et al, ${ }^{16}$ reported that slap or a fist by a spouse or lover was responsible for more than half of cases of TTMP in their study. Spousal abuse is both a legal and a social issue, however this action should be condemned. Equally condemnable is the assault from state security personnel, and they are also enjoined to desist from assault of the citizenry even if a criminal act has been committed.

We observed that self-inflicted injury was also common cause of TTMP in this study. Despite being symptomatic, most patients with self-inflicted injuries were hesitant to divulge history of ear picking using different objects. It was only after the discovery of the TTMP that the patients were re-questioned and agreed to have used different objects including cotton buds, hair-pins, and match sticks to pick their ears. Injuries from these different objects along with RTAs and instrumental removal of foreign bodies from the ears accounted for the bulk of penetrating injuries found in this study. Ear picking accounted for $90.3 \%$ of direct ear injuries seen in Japan, ${ }^{21}$ and $19.3 \%$ of those seen in Germany. ${ }^{20}$ The habit of earpicking with different objects should be discouraged, in order to minimize the incidence of TTMP among others. Road traffic accidents (RTA) was also prominent cause in this study. Our center is a hospital located within an axis of two major linkage roads and RTA cases are often presented at the center for initial assessments.

However most of these patients $(n=32 / 42)$ had their data excluded from the study because they were referred to other centers for assessments, while some others had moved to their original places of domicile and were lost to follow-up re-evaluation. 
Irrespective of the cause or mechanism of injury, the concern is healing and closure of the TTMP without residual morbidity. Complications like middle ear infections, perilymph fistula, facial paralysis, and hearing impairment should be prevented. Studies ${ }^{16,19,22}$ have reported that at least $85 \%$ of TTMP close spontaneously and heal without any active intervention within 3 to 4 weeks of injury. Animal studies have demonstrated that perforations heal by means of epithelial migration which starts from the outer epithelial layer, with later healing of the lamina propria and the mucosal layer. ${ }^{23}$ The epithelial generation center is located near the annulus and the handle of the malleus. ${ }^{24}$ Otologists opined that patients with all forms of traumatic conductive hearing loss can be initially managed conservatively, and that even suspected ossicular chain disruptions have a high rate of spontaneous reparation. ${ }^{25}$ The management of TTMP that we employed was the conservative way of inactive intervention to allow for spontaneous closure. It involved leaving the ear unpacked, prevention of infection and deploying systemic antibacterial in patients at risk of infection. Two weekly appointments were initiated for patients' re-evaluation and outcome of treatment checked after six weeks of injury.

The outcome of the injury in terms of healing of the perforation was adjudged good in majority of the ears, however $19.7 \%$ had poor outcomes. The outcome may be related to the location of the perforation which could be either in the antero-inferior or in the postero-superior quadrant. There were however some perforations that traversed the two quadrants and others that were not distinct to classify (undefined). Antero-inferior quadrant perforations involved mainly the pars tensa, and is assumed to be favorable to heal, while postero-superior quadrant perforations often involved the pars flaccida and is less favorable to heal. Previous studies ${ }^{21,26}$ had reported perforations occurred more in the antero-inferior quadrant as also found in this study. Postero-superior perforations was associated with poor outcome in this study. Other studies have however reported contrary findings that the rate of spontaneous healing of TTMP did not vary with location of the TM perforation. ${ }^{26,27}$ One reason for this difference may be the relatively small sample sizes from these two studies ${ }^{26,27}$ compared with the larger sample sizes from other reported series. We ameliorated interobserver subjectivity in site and size of perforations in this study by allowing two otologists to view the perforation, make independent diagrammatic sketches of same and reconcile any difference. However, a video-otoscope is capable of generating still and video images of the tympanic membrane and it is a better tool for such an assessment. ${ }^{28}$ Although we do not have this equipment in our center yet, we propose that video otoscopy should be the standard tool used for assessment of TM perforations.
This will reduce the subjectivity and inter-observer errors, and also will allow better comparisons of TM perforations. Another factor that influenced healing of the TTMP in this study was the size of the perforation. We compared sizes of the perforations relative to the circumference of the TM. While the sizes ranged from 10 to $75 \%$, the median of $33 \%$ was used to categorize such into either a small or large-sized perforation. It has been noted that non-healing was associated with large-sized TTMP. ${ }^{18}$ The hypothesis is that large-sized perforations affect the malleus and umbo at the insertion on the TM and would disturb the middle ear sound conducting mechanism. Poor outcome can also be regarded as a slow healing rate or delayed closure time of the TTMP. Lou et al ${ }^{16}$ reported that although the perforation that involved malleus or umbo damage did not significantly affect the healing rate, a significantly prolonged closure time was observed in TMs with such damage compared with those without it. The rate of spontaneous healing of TTMP reportedly varied inversely with the size of the perforation. ${ }_{26,29}$ Penetrating injuries were also associated with poor healing outcome in this study. Penetration of the TM by objects may lead to ossicular chain disruptions in the middle ear. ${ }^{4}$ It may also be complicated with suppurative middle ear disease if the penetrating object harbour some infective organisms as seen in some of our patients. Orji and Agu reported that healing of TTMP was delayed by middle-ear infection and confirmed that penetrating injuries sustained through the ear canal was an important risk factor in predicting non-healing of TTMP. ${ }^{26}$

There is inconsistent reportage concerning the influence of ear discharge or infection on the healing outcome of TTMP. ${ }^{16,29,30}$ Unfortunately we could not assess if the healing rate was affected by ear discharge or associated infection in this study. We had few patients with serosanguinous ear discharge and fewer ones with purulent discharge who had ear swab cultured for micro-organisms, but we could not do proper comparative analysis. A limitation to the study was the fact that many patients defaulted, and some were not followed-up for sundry reasons which drastically reduced the sample size.

This study thus concludes that TTMP was common in young adult males, caused often by assaults, presented with ear blockage/hearing loss and tinnitus, perforations were located in antero-inferior quadrant of the TM most of which healed well. The factors associated with poor healing were postero-superiorly-located perforations, large sized perforations and penetrating injuries to the TM. 


\section{REFERENCES}

1. Guenzani S, Mereu D, Messersmith M, Olivari D, Arena M, Spanò A. Inner-ear decompression sickness in nine trimix recreational divers. Diving $\mathrm{Hy}$ perb Med. 2016;46:111-6.

2. Yetiser S, Hidir Y, Birkent H, Satar B, Durmaz Traumatic ossicular dislocations: etiology and management. Am J Otolaryngol. 2008;29:31-6.

3. Eagles K, Fralich L, Stevenson JH.Ear trauma. Clin Sports Med. 2013;32:303-16.

4. Neuenschwander MC, Deutsch ES, Cornetta A, Willcox TO. Penetrating middle ear trauma: a report of 2 cases. Ear Nose Throat J. 2005;84:32-5.

5. Conoyer JM, Kaylie DM, Jackson CG. Otologic surgery following ear trauma. Otolaryngol Head Neck Surg. 2007;137:757-61.

6. Jellinge ME, Kristensen S, Larsen K. Spontaneous closure of traumatic tympanic membrane perforations: observational study. $J$ Laryngol Otol. 2015;129:950-4.

7. Smith M, Darrat I, Seidman M. Otologic complications of cotton swab use: one institution's experience. Laryngoscope. 2012;122:409-11.

8. Lou Z, Yang J, Tang Y, Fu Y. Topical application of epidermal growth factor with no scaffold material on the healing of human traumatic tympanic membrane perforations. Clin Otolaryngol. 2016 Jan 30. doi: 10.1111/coa.12627. [Epub ahead of print]

9. Bilge A, Gunes A, Dagli M, Koybasioglu FF, Guvey A. The impact of topical and systemic enoxaparin sodium use on traumatic tympanic membrane perforation and myringosclerosis. Eur Arch Otorhinolaryngol. 2016 Jan 21. [Epub ahead of print]

10. Güneş A, Mutlu M, Akın İ, et al. The Impact of Systemic and Local Administration of Ascorbic Acid on Traumatic Perforation of Tympanic Membrane and Myringosclerosis. J Int Adv Otol. 2015;11: 48-52.

11. Lee JH, Lee JS, Kim DK, Park CH, Lee HR. Clinical outcomes of silk patch in acute tympanic membrane perforation. Clin Exp Otorhinolaryngol. 2015;8:117-22.

12. Levin B, Redmond SL, Rajkhowa R, Eikelboom RH, Atlas MD, Marano RJ. Utilising silk fibroin membranes as scaffolds for the growth of tympanic membrane keratinocytes, and application to myringoplasty surgery. J Laryngol Otol. 2013;127 Suppl 1:S13-20.

13. Park MK, Kim KH, Lee JD, Lee BD. Repair of large traumatic tympanic membrane perforation with a Steri-Strips patch. Otolaryngol Head Neck Surg. 2011;145(4):581-5.

14. Oyewole EA. Ear trauma in Sagamu Nigeria. Nigerian Medical Practitioner. 2003; 43: 101-3.
15. Afolabi OA, Aremu SK, Alabi BS, Segun-Busari S. Traumatic tympanic membrane perforation: an aetiological profile. BMC Res Notes. 2009 21;2:232.

16. Lou ZC, Lou ZH, Zhang QP. Traumatic tympanic membrane perforations: a study of etiology and factors affecting outcome. Am $J$ Otolaryngol. 2012;33:549-55.

17. Sarojamma S, Raj S, Satish HS. A Clinical Study of Traumatic Perforation of Tympanic Membrane. IOSR Journal of Dental and Medical Sciences (IOSR-JDMS). 2014; 13 :24-28.

18. Orji FT. Non-explosive blast injury of the tympanic membrane in Umuahia, Nigeria. Niger $J$ Med. 2009; 18:365-9.

19. da Lilly-Tariah OB, Somefun AO. Traumatic perforation of the tympanic membrane in University of Port Harcourt Teaching Hospital, Port Harcourt. Nigeria. Niger Postgrad Med J. 2007;14: 121-4.

20. Kraus F, Hagen R. The Traumatic Tympanic Membrane Perforation - Aetiology and Therapy.[in German] Laryngorhinootologie. 2015;94:596-600.

21. Yamazaki K, Ishijima K, Sato H. A clinical study of traumatic tympanic membrane perforation. [in Japanese] Nihon Jibiinkoka Gakkai Kaiho. 2010;113:679-86.

22. Lou ZC. Spontaneous Healing of Traumatic Eardrum Perforation: Outward Epithelial Cell Migration and Clinical Outcome. Otolaryngol Head Neck Surg. 2012; 147:1114-9.

23. Araújo MM, Murashima AA, Alves VM, Jamur MC, Hyppolito MA. Spontaneous healing of the tympanic membrane after traumatic perforation in rats. $\mathrm{Braz} J$ Otorhinolaryngol. 2014;80:330-8.

24. Wang WQ, Wang ZM, Chi FL. Spontaneous healing of various tympanic membrane perforations in the rat. Acta Otolaryngol. 2004;124:1141-4.

25. Grant JR, Arganbright J, Friedland DR. Outcomes for conservative management of traumatic conductive hearing loss. Otol Neurotol. 2008;29:344-9.

26. Orji FT, Agu CC. Determinants of spontaneous healing in traumatic perforations of the tympanic membrane. Clin Otolaryngol. 2008;33:420-6.

27. Mehta RP, Rosowski JJ, Voss SE, O'Neil E, Merchant SN. Determinants of hearing loss in perforations of the tympanic membrane. Otol Neurotol. 2006;27:136-43.

28. Ibekwe TS, Adeosun AA, Nwaorgu OG. Quantitative analysis of tympanic membrane perforation: a simple and reliable method. J Laryngol Otol. 2009 Jan;123:e2. doi: 10.1017/S0022215108003800.

29. Lou ZC, Tang YM, Yang J. A prospective study evaluating spontaneous healing of aetiology, size and type-different groups of traumatic tympanic membrane perforation. Clin Otolaryngol. 2011;36:450-60. 
30. Albera R, Dagna F, Filippini C, Albera A, Canale A. Ossicular Chain Lesions in Tympanic Perforations and Chronic Otitis Media without Cholesteatoma. $J$ Int Adv Otol. 2015;11:143-6 